\title{
Does Collaboration Facilitate Data Use in Schools?
}

\author{
Jonathan Supovitz \& Katrina Morrison \\ Graduate School of Education \\ Consortium for Policy Research in Education \\ University of Pennsylvania
}

Received: April 4, 2015 Accepted: April 27, 2015 Published: May 1, 2015

doi:10.5296/jse.v5i2.7379 URL: http://dx.doi.org/10.5296/jse.v5i2.7379

\begin{abstract}
School teachers are often encouraged to analyze data in groups or teams, and strong collaborative environments are seen as an important context for effective data use. This study investigates the relationship between teacher reports of collaboration and two dimensions of data use. in schools. The data analyzed for this study were collected from a survey of teachers in 37 schools in a large urban northeast school district in the United States and analyzed in a multi-level framework. Findings show a strong and significant relationship between collaboration and data use, even after controlling for individual teacher background characteristics and school culture characteristics. These results affirm the hypothesis that data use is commonly a collaborative activity in schools and that collaboration strengthens data use practices.
\end{abstract}

Keywords: Collaboration facilitates data use, Teacher reports of collaboration, Data use, School reform, Multi-level modeling 


\section{Introduction}

The past decade has seen an explosion of available student performance data for schools and teachers (Supovitz, 2009). This focus on data use is driven by three complementary and inter-related factors. First, policy-makers view accountability as a low-cost mechanism to drive changes in classrooms and schools (McDonnell 2005) and consequently there has been an expansion in the amount of testing across the country (Hamilton, Stecher \& Klein, 2002). Second, advances in technology have allowed for quicker turnaround to teachers of student performance data and more flexible access (Stringfield, Wayman \& Yakimowski-Srebnick, 2005). Third, rational models of decision-making encourage the use of data to inform the choices of decision-makers (Simon, 1955; Lindblom \& Cohen, 1979). The rise in data available in schools raises questions about how teachers should effectively analyze them.

A central aspect underlying many models of data use in schools is the collaborative aspect of this activity. Models for examining data in schools are almost always conceived of as being done by groups of teachers and/or administrators (Bernhardt, 1998; Earl \& Katz, 2006; Boudett, City \& Murnane, 2005). In most data use models, school faculty are encouraged to analyze data in groups or teams, and strong collaborative environments are seen as an important context for effective data use. While proposed models for examining data suggest that this be done collaboratively, and conceptual frames incorporate collaboration, we are aware of no research that has examined this connection empirically. The relationship between dimensions of collaboration in schools and the use of data is the central purpose of this investigation. By examining survey data from 37 schools in a large urban school district, we explore the relationships between collaboration and data use, as well as the mediating roles of both individual teacher and school characteristics.

\section{Literature Review}

Driven by high stakes accountability policies and facilitated by increased technological capabilities, the past decade has seen a tremendous expansion of available student performance data for school and teachers (Supovitz, 2009). Researchers have catalogued the use of data in schools in a variety of ways, often categorized by their frequency of test administration or level of use. Wiliam and Leahy (2006) organized the use of data by teachers as a function of the testing feedback cycle, distinguishing between short, medium, and long cycle assessments. They defined short cycle assessments as those that gave teachers feedback within the course of a single lesson; medium cycle assessments as generating feedback from lesson to lesson but typically within units; and long cycle assessments as feedback beyond an instructional unit, from more than four weeks to a year after data were gathered. Supovitz \& Klein (2003) organized data use by the level of schooling for whom they provided information. In their conception, data were organized by classroom, grade and school levels, whereby classroom level data use comprised formative assessments for teachers; grade level data were those examined by grade level or subject matter teams for pacing, curricular adjustments, or student grouping; and school level data were examined by school leaders for more strategic decision-making. 
The perceived value of using data in schools to inform practice is bolstered by the relationship between data use and important school outcomes. A number of case studies of schools and districts has identified the systematic and deliberate use of data as an important factor in effective organizational performance (Snipes, Doolittle \& Herlihy, 2002; Togneri \& Anderson, 2003; Supovitz, 2006; Datnow, Park, \& Wohlstetter, 2007; Christman et al. 2009). A few studies have examined the relationship between data use and classroom practices. Chrispeels, Castillo \& Brown (2000), for example, examined factors about school leadership teams that were related to effective teaching and learning. Using survey data from 142 school leadership teams they found that the use of data - defined as a leadership team focus on student assessments, analyzing student work, and basing decisions about curriculum and teaching on data - had one of the most powerful effects on teaching and learning. The authors concluded that "the centrality of teams' use of data may be helping to harness and focus team and school energy and resources to address a critical need" (p. 43).

The literature on data use in schools also indicates both that data are often examined in groups and that the collaborative nature of data use results in a more productive decision-making process. In a case study of data use in high schools Lachat \& Smith (2005) found that involving teachers in data analysis is essential. Examining a teacher professional development initiative, Love (2000) reported the importance of engaging school staff in collaborative problem solving around data. Chrispeels, Castillo \& Brown (2000) described how data were analyzed by school leadership teams. Steele and Boudett (2009) found that collaborative meetings amongst teachers, including grade level meetings and school-level professional development meetings were important venues for productive conversations about data. Datnow, Park and Wohlstetter (2007) conducted case studies of data use in four high performing school systems. They found several common strategies that the systems employed to use data to improve instruction. First, the systems built capacity to analyze data through professional development and ongoing support on how to use data as well as the modeling of data use and data discussions. Second, they provided structures and time for teachers to examine data collaboratively.. And third, they facilitated organizational learning by connecting faculty across schools to share data and improvement strategies. All of these studies reinforce the notion that effective data use in schools is a collaborative endeavor.

Other researchers have focused specifically on team formulations within schools and their influence on data use. Young (2006) conducted four year-and-a-half long case studies of grade level teams' use of data. She observed team meetings around both external (i.e., state test) and internal (i.e., student work) data and interviewed coaches, teachers, and administrators. She found that the teams were characterized by different levels of team cohesion and joint work and that the development of team norms and agenda setting facilitated or hindered their efforts to analyze data productively and incorporate it into their instruction. Supovitz, Merrill \& Conger (2010) examined the use of data in 11 professional learning communities (PLCs) in schools in a suburban school district. They conducted weekly observations of the PLCs and categorized the ways that the teams used data. Data use in these PLCs ranged from examining student test scores, behavioral data, and writing samples of particular students to discussing the design of the measures that were used to 
collect student performance data. They identified examples of team member collaboration around data and found that collaboration amongst members within the PLCs generally fostered deeper data use. These and other case studies support the notion that collaboration can facilitate more effective data use in schools.

There is also important theoretical grounding to support the contention that individuals might find benefit from examining data with colleagues rather than individually. Organizational theorists have suggested that individuals tend to navigate uncertain environments and complex activities collectively. March \& Olsen (1975), for example, viewed collective processes as one way of dealing with uncertainty and ambiguity. Daft \& Weick (1984) portrayed decision-making in organizations as a group of decision-makers scanning the environment for information, collectively making sense of the information, and converting it into organizational action. Kim (1993) viewed the development of shared mental models as a key process of developing organizational learning. Research on policy interpretation and sense-making suggests the importance of collective sense-making. Spillane (1999) found that individuals use group activities to make sense of information and interpret policies. Coburn (2001) found that teachers make sense of things through conversation and interaction with colleagues and construct shared understandings.

Thus, while both research and theory on data use and decision-making in schools and other organizations has found that the examination of data is often done in group settings, there have been no quantitative studies examining the relationship between collaboration and data use. In this paper we seek to establish an empirical relationship between teacher collaboration and individual and school-wide data use. Our research questions for this investigation are:

1. What is the relationship between teacher reports of collaboration and both teacher use of individual student data and use of data for school-wide purposes?

2. What individual teacher characteristics are associated with teacher use of individual student data and use of data for school-wide purposes?

3. What school factors are associated with teacher use of individual student data and use of data for school-wide purposes?

\section{Research Design}

In this study we focus on the relationship between teacher collaboration and two dimensions of data use, individual teacher data use and school-wide data use. Using multi-level modeling to include a set of both individual teacher and school covariates, we examine both the relationship between collaboration and data use controlling for these factors, as well as their direct associations with individual teacher and school-wide data use. In this section of the article we describe the site and sample, the survey instrument, the resulting data, and the analytic framework we employed to produce the study results.

\section{Data Collection}

The data for this study were collected via a school faculty survey that was part of an evaluation of a school leadership intervention in a large urban northeast school district in the 
United States. The survey was administered in May and June of 2009 largely during faculty meetings in each of 37 schools participating in the evaluation. As a consequence of administration in a controlled environment, the research team received a respectable average response rate of $79 \%$ on the survey, with a school standard deviation of $17 \%$. Seven schools had $100 \%$ response rates, while three had around a $50 \%$ response rate.

The survey asked school faculty questions that focused on themselves, their school environment, their use of data, and their leadership and teaching practices. Some parts of the survey were customized for the evaluation, while other parts consisted of well established scales that have been used in previous survey research. The school culture and climate scales on the survey, for example, have their lineage in the work of the Chicago Consortium for School Research and Study of Instructional Improvement (Consortium on Chicago School Research, 2000; Study of Instructional Improvement, 2000).

\section{Measures}

From the survey, we identified two dimensions of data use, which were used as dependent variables in this analysis. The first, Use of Individual Student Data, is a five-item scale that was made up of items that asked teachers the extent to which they used individual student data to inform a range of decisions. These included using data to identify students for remedial assistance, setting learning goals for individual students, tailoring instruction for individual students, and assigning students to classes or groups.

The second dimension of data use derived from the survey we called School-Wide Data Use. This is a four-item scale measuring the extent to which data were used for school-wide purposes. These purposes included setting school improvement goals, determining topics for professional development, and identifying areas where teachers need to strengthen their content knowledge or teaching skills. The exact items and reliabilities of these and subsequently described survey scales are shown in Appendix A.

The survey also collected information on a set of individual respondent characteristics, including gender, ethnicity, years of experience, education level, and grade level taught. We used experience, education level and grade level taught because we could hypothesize that they might be related to data use, but decided to omit ethnicity and gender from our analyses because we had no reason to believe these would be connected to classroom or school-wide use of data.

In addition, the survey contained a number of questions that asked teachers about dimensions of the school environment. Of primary interest were the frequency of teachers' instructional conversations with peers and frequency of teacher meetings with peers, which we use to represent the degree of teacher collaboration in the school. Instructional Conversations is a six-item scale which reflects the frequency that teachers have discussions with their colleagues about professional topics including instruction, student behavior, curriculum, and standards. Teacher Meetings is a single item that asks teachers how often they have scheduled meetings with other teachers in the school to discuss and plan curriculum and 
teaching approaches. This item had 5 response options, ranging from never to more than once a week.

We also used three other scales in our models to characterize dimensions of school climate that we hypothesized might contribute to the degree of data use in schools. The first, Organizational Climate, represents teachers' perceptions of the safety and levels of respect that they see in their school environment. Organizational Climate is a nine-item scale which reflects the degree to which teachers perceive that they face obstacles in different dimensions of the climate of their school. We hypothesize that the organizational climate of the school might facilitate or impede teachers' use of data. The second, Academic Press, represents the sense that the faculty has high expectations for student effort and academic performance. Academic Press is a four-item scale which indicates the extent to which teachers perceive that their colleagues are pushing for high expectations and high quality work and performance from students. We hypothesize that academic press would be positively associated with data use. The third scale we used was Collective Responsibility, a five-item scale. The Collective Responsibility scale measures the degree to which teachers perceive that all faculty members feel responsible for the student body and the broader school environment beyond the students or duties assigned to them. We hypothesize that collective responsibility would also be positively associated with data use, particularly the measure of school-wide data use.

Finally, our models included variables that represented the performance level of the schools in the sample. School performance was calculated as the average percent of students proficient in reading and mathematics in grade 3 (elementary school), grade 6 (middle school), or grade 11 (high school) in 2009. This allowed us to control for school performance level in our models of data use.

\section{Data}

Survey data were collected from over 1,300 teachers and school administrators in 37 schools in a large Northeast school district. Of the 37 schools, 25 were elementary (predominantly grades K-8, although some were K-5 or K-6); 3 were middle schools (grades 6-8); and 9 were high schools (grades 9-12). For this study only the teacher survey data, not the administrator data, were used, producing an initial dataset of 1,306 teachers in grades K-12.

We handled missing data through a multi-step process. First, we identified the percentage of missing items within each scale for each participant. Those individuals who had more than 50 percent of the items missing for a scale were removed from the dataset. This resulted in 37 teachers being removed. The remaining missing data within each scale were imputed using multiple imputation based upon the items within the scale. Next, we identified an additional 23 teachers who did not respond to the number of meetings they attended. Since this was a variable of primary interest, we conservatively removed these 23 teachers from the final dataset. Finally, in the remaining data there were 27 cases in which the respondent did not provide their grade level, education level, or experience, and these were also removed because we had no other information from which to impute them. The final dataset consisted of 1,166 cases. 
Analytic Method

The analyses for this study were performed within a multilevel modeling framework in order to account for the nested nature of teachers within schools and allow for the appropriate partitioning and modeling of variance at the individual and school levels (Raudenbush \& Bryk, 2002).

The fully specified linear model for the teacher level, or level 1, of the analysis can be written as:

$Y_{i j}=\beta_{0 j}+\beta_{1}$ (Collaboration $)+\beta_{2}$ (Meetings $)+\beta_{3}$ (Teacher Experience $)+\beta_{4}$ (Bachelors Degree $)$ $+\beta_{5}$ (Masters Degree Plus) $+\beta_{6}$ (Elementary Teacher $)+\beta_{7}$ (High School Teacher $)+$ $\beta_{8}$ (Teacher Perception of Organizational Climate) $+\beta_{9}$ (Teacher Perception of Collective Responsibility of Faculty) $+\beta_{10}$ (Teacher Perception of Academic Pressure $)+\varepsilon_{i j}$

where $Y_{i j}$ represents data use and $i$ and $j$ teachers and schools, respectively. In addition, $\beta_{0}$ represents the intercept for mean teacher data use and the model contains teacher-level measures of collaboration, frequency of meetings, education level, school level, teacher perception of organizational climate, teacher perception of collective responsibility of the faculty, and teacher perception of academic pressure. Finally, the model contains a teacher-level residual, represented by $\varepsilon_{i j}$.

The school-level portion of the model, or level 2, is different from the individual-level portion of the model. At level 2, the intercept for mean teacher data use is modeled as a function of a grand mean and school level means of three scales included at the individual level (organizational climate, collective responsibility, and academic pressure), as well as the average percent of proficient mathematics and English language arts students in the school, and a school-level residual. More formally, the school-level portion of the model can be written as:

$\beta_{0 j}=\gamma_{00}+\gamma_{01}($ School Climate $)+\gamma_{02}($ Collective Responsibility $)+\gamma_{03}($ Academic Pressure $)+$ $\gamma_{04}($ Percent Proficient $)+\tau_{j}$

The rationale for including the school level means of variables also entered at level 1 (school climate, collective responsibility, and academic pressure) is that there may be both individual effects of these variables based upon teachers' individual perceptions, as well as school level collective effects associated with teachers working in a school with a predominant attitude towards these school cultural factors.

Using these model specifications, we conducted two sets of parallel analyses, one set for each of our outcome variables (individual teacher data use and school-level data use). Each set of 
analyses consisted of four models. The first model was a null model that we used to partition the variance between level 1 (teachers) and level 2 (schools). The second model contained only our two dimensions of teacher collaboration of primary interest, the teacher collaboration scale and the teacher meetings variable (both standardized). The third model added the set of individual teacher characteristics, including teacher experience, education level, and school level. The fourth and final model added the set of school characteristics at both the teacher and school levels. All level-2 variables were added as fixed effects and were centered around the grand mean.

\section{Results}

The results of this study are presented in three sections. First we provide the descriptive statistics for the variables included in the analyses. Second, we present the results of predictors of teachers' use of individual student data. Third, we present the results of teachers' use of data for school-wide purposes. Each set of models allows us to look at both the effects of our primary predictors to collaboration on data use, but also how these predictors behave as individual and school level variables are added to the models.

\section{Descriptive Statistics}

The descriptive statistics for each of the variables included in our analyses are shown in Table 1. Teachers in our sample reported that they used individual student data slightly more, on average, than they used data for school-wide purposes. The two main predictor variables of interest were the frequency of instructional conversations and the frequency of teacher meetings, which we conceptualized as different dimensions of teacher collaboration. The scale for teacher collaboration had a mean of 2.79 on its five-point scale, with a standard deviation of just under 1 . The mean of the frequency of teacher meetings was 3.24, which represented about 2-3 times per month, with a fairly wide standard deviation of 1.23. The correlation between these two measures of teacher collaboration was .397 , which indicated that although the overlapped, they were measuring different dimensions of teacher collaboration. Before proceeding with the final analyses, we standardized each of these measures independently, giving each a mean of 0 and a standard deviation of 1 . The purpose of doing this was so that we could compare the magnitude of their effects on data use.

Several other independent variables were also included in our analyses. Teachers reported that, on average, their experience was 15 years, with 68 percent of the sample reporting experience between almost 5 and almost 26 years. A quarter of the sample had a Bachelor's degree, while almost one third had a Master's degree. Forty three percent had either additional coursework beyond their masters or a doctorate. In our preliminary analyses of the data, we found that only 22 teachers reported that they had doctorates, so we combined these people with the 475 who reported a Master's plus coursework. Half the teachers in the sample taught in grades K-5. Almost two hundred of the teachers in the sample, or $17 \%$, reported that they taught in grades 6-8. Finally, a third of the sample, or 385 teachers, taught in grades 9-12. 
Table 1. Descriptive Statistics for Survey Respondents $(n=1,166)$

Variable

Dependent Variables

Use of Individual Student Data (6 items on a 4 point scale)

Use of Data for School-wide Purposes (4 items on a 4 point scale)

\section{Independent Variables}

Individual Teacher Characteristics $(\mathrm{n}=1,166)$

Instructional Conversations (6 items on a 5 point scale)

Teacher Meetings (1 item on a 7 point scale)

Years of Teacher Experience

Education Level

Bachelor's Degree

Master's Degree

Master's Degree plus coursework or doctorate

Grade Taught

K-5 Grade Teachers

6-8 Grade Teachers

9-12 Grade Teachers

Academic Pressure (4 items on a 6 point scale)

Organizational Climate ( 9 items on a 4 point scale)

Collective Responsibility (5 item on a 5 point scale)

$\underline{\text { School Characteristics }(\mathrm{n}=37)}$

Academic Pressure (4 items on a 6 point scale)

Organizational Climate ( 9 items on a 4 point scale)

Collective Responsibility (5 item on a 5 point scale)

Percent Proficient
Descriptive Statistics

$$
\begin{aligned}
& \mu=3.00 ; \mathrm{sd}=.74 \\
& \mu=2.70 ; \mathrm{sd}=.81
\end{aligned}
$$

$\mathrm{M}=2.79 ; \mathrm{sd}=.917$

$\mathrm{M}=3.24 ; \mathrm{sd}=1.23$

$\mu=14.99 ; \mathrm{sd}=10.74$

$\mathrm{N}=296(25 \%)$

$\mathrm{N}=373$ (32\%)

$\mathrm{N}=497$ (43\%)

$\mathrm{N}=583(50 \%)$

$\mathrm{N}=198$ (17\%)

$\mathrm{N}=385(33 \%)$

$\mu=5.06 ; \mathrm{sd}=.91$

$\mu=2.39 ; \mathrm{sd}=.62$

$\mu=3.60 ; \mathrm{sd}=.83$

$$
\begin{gathered}
\mu=5.06 ; \mathrm{sd}=.29 \\
\mu=2.39 ; \mathrm{sd}=.41 \\
\mu=3.60 ; \mathrm{sd}=.32 \\
\mu=56.62 ; \mathrm{sd}=20.63
\end{gathered}
$$

Teachers were also asked about their individual perceptions of three dimensions of school culture. Academic pressure was their individual perceptions of the extent to which teachers in their school had high expectations for student effort and academic performance. Teachers were in solid agreement with these questions; on this six-point scale, the average was 5.06, with a standard deviation of .91. A second school culture scale was organizational climate, which assessed teachers' perceptions of safety and respect in their school environment. The mean of this measure was 2.39, with a standard deviation of .62. The final school culture measure was collective responsibility, which was a measure of teachers' perceptions of what proportion of their peers felt responsible for the broader school environment. The average 
response was 3.6 on this scale, which meant that, on average, teachers felt that between half and most of the teachers in their school felt responsible for the broader school environment. In preliminary analyses, we examined the correlations between these school culture indicators and found their correlations to be around .3, indicating some overlap, but substantial distinctness.

The three school culture scales (academic pressure, organizational climate, and collective responsibility) were also aggregated to the school level for each of the 37 schools in the sample, to provide a sense of the school faculties' collective perception of each of these indicators. The aggregation to the school level did not change the mean values for these scales, but reduced their variability, thus compressing their standard deviations. A final school level measure that was utilized in our analyses was the percent of students in the school who were proficient on the state test. The purpose of this was to include a measure of the academic performance of the schools in the sample. The percent proficient was the average of the percent proficient in mathematics and the percent proficient in reading that was reported on the state website for 2009. The average percent proficient in our sample was almost 57 percent, with a wide standard deviation of almost 21 percent. This indicates a fairly broad range of different performing schools in the sample.

\section{Predictors of Teacher Use of Individual Student Data}

Our first set of analytic models examined the variables related to teacher use of individual student data. Table 2 shows the results of each of four models predicting teacher use of individual student data. Model 1 is a null model containing no predictors, but specifying the nesting of teachers into schools. When the null model was analyzed, the total variance was .530 with (sigma squared) being .452 and (tau) being .078 . That is $85 \%$ of the overall unexplained variance was at the individual teacher level and $15 \%$ of the overall unexplained variance was at the school level.

Model 2 includes the primary independent variables of interest about teacher collaboration into the model. When the two teacher level predictors were included in the model, there was a variance reduction at the teacher level from .452 to .392 , a $13.3 \%$ reduction. This indicates that the two teacher level predictors measuring the frequency that teachers collaborate with one another explained $13 \%$ of the explainable variation at the individual level. 


\section{Macrothink}

Table 2. Teacher Use of Individual Student Data

\begin{tabular}{|c|c|c|c|c|}
\hline & Model 1 & Model 2 & Model 3 & Model 4 \\
\hline \multicolumn{5}{|l|}{ Level 1} \\
\hline Intercept & $\begin{array}{l}3.052 * * * \\
(.050)\end{array}$ & $\begin{array}{l}3.048 * * * \\
(.041)\end{array}$ & $\begin{array}{l}3.091 * * * \\
(.067)\end{array}$ & $\begin{array}{l}1.422 \\
(.945)\end{array}$ \\
\hline Instructional Conversations & & $\begin{array}{l}.212 * * * \\
(.020)\end{array}$ & $\begin{array}{l}.211 * * * \\
(.021)\end{array}$ & $\begin{array}{l}.198 * * * \\
(.021)\end{array}$ \\
\hline Teacher Meetings & & $\begin{array}{l}.105 * * * \\
(.022)\end{array}$ & $\begin{array}{l}.098 * * * \\
(.023)\end{array}$ & $\begin{array}{l}.092 * * * \\
(.020)\end{array}$ \\
\hline Teacher Experience & & & $\begin{array}{l}.003 \\
(.002)\end{array}$ & $\begin{array}{c}.002 \\
(.002)\end{array}$ \\
\hline Bachelor's & & & $\begin{array}{l}-.023 \\
(.050)\end{array}$ & $\begin{array}{l}-.033 \\
(.049)\end{array}$ \\
\hline Master's Plus & & & $\begin{array}{l}.097 \sim \\
(.045)\end{array}$ & $\begin{array}{l}.092 \sim \\
(.044)\end{array}$ \\
\hline K-5 Grade Teacher & & & $\begin{array}{l}-.061 \\
(.057)\end{array}$ & $\begin{array}{l}-.051 \\
(.056)\end{array}$ \\
\hline 9-12 Grade Teacher & & & $\begin{array}{l}-.038 * * * \\
(.074)\end{array}$ & $\begin{array}{l}-.259 * \\
(.084)\end{array}$ \\
\hline Organizational Climate & & & & $\begin{array}{l}-.020 \\
(.039)\end{array}$ \\
\hline $\begin{array}{l}\text { Collective } \\
\text { Responsibility } \\
\text { Academic Pressure }\end{array}$ & & & & $\begin{array}{l}.092 * * \\
(.027) \\
.069 * * \\
(.023)\end{array}$ \\
\hline \multicolumn{5}{|l|}{ Level 2} \\
\hline Organizational Climate & & & & $\begin{array}{c}.205 \\
(.126)\end{array}$ \\
\hline Collective & & & & .125 \\
\hline Responsibility & & & & $(.153)$ \\
\hline Academic Pressure & & & & $\begin{array}{l}-.017 \\
(.185)\end{array}$ \\
\hline Percent Proficient & & & & $\begin{array}{c}.004 \\
(.002)\end{array}$ \\
\hline \multicolumn{5}{|l|}{ Model Statistics } \\
\hline Sigma Squared & .452 & .392 & .389 & .380 \\
\hline Tau & .078 & .049 & .017 & .017 \\
\hline
\end{tabular}

$* * * \mathrm{p}<.001 ; * * \mathrm{p}<.01 ; * \mathrm{p}<.05 ; \sim \mathrm{p}<.10$

The significance level of these variables indicated that both frequency of instructional conversations and frequency of teacher meetings were positively and significantly related to teacher use of individual student data. That is, the more teachers had instructional 
conversations and the more meetings they reported having, the more extensively they reported using individual student data. As both of these measures of collaboration were standardized, this means that each standard deviation of increased instructional conversations was associated with .2 additional units of individual student data, on the four-point scale. Frequency of teacher meetings, while also significant, was about one half as strong a predictor of teacher use of individual student data in comparison to teacher collaboration.

Model 3 adds variables of teacher experience, education, and grade level. The first thing to note is that both the variables of instructional conversations and teacher meetings remain significant and of about the same magnitude after controlling for the additional teacher variables. Viewed in a different way, teacher experience was not a significant predictor of use of individual student data, after controlling for the other characteristics in the model. Additionally, there was only a slight difference in teacher individual student data use by education level, with teachers with more than a Master's degree reporting slightly more data use than teachers with masters degrees. However, there was no significant difference in individual student data use between teachers with Bachelor's degrees and teachers with Masters degrees, after controlling for collaboration and the other teacher characteristics contained in the model. Finally, high school teachers reported significantly less individual student data use than did middle school teachers, but there were no significant differences between elementary and middle school teachers, after controlling for the other variables included in the model. In this model the within school variation has been reduced to .389 . This indicates that the level-one predictors, taken together, explain $14 \%$ of variation at the teacher level.

Model 4 shows the full model, containing both individual teacher and school level factors. Again, instructional conversations and teacher meetings are both significant predictors of teacher use of individual student data, even after controlling for the individual teacher and school level variables included in the model. Organizational climate is not a significant predictor of data use, at either the teacher or school level. At the teacher level, reports of individual perceptions of collective responsibility and academic press are both positively and significantly related to teacher use of individual student data, but these factors are not significant at the school level. This indicates that teachers' individual perceptions of the collective responsibility of their peers, and their individual perceptions of the academic orientation of their peers are both related to higher levels of data use. Finally, there was no difference in teacher use of individual student data among different performing schools in the sample.

\section{Predictors of School-Wide Data Use}

The second set of models examined the relationship between teacher collaboration and School-wide data use, controlling for individual teacher characteristics and school culture indicators. The models examining these relationships are shown in Table 3. Model 1 is a null model, containing only the level 1 and level 2 configurations. A decomposition of the variance in the null model shows that the total variance was .648. The total variance, (sigma 
squared) was .601 and (tau) was .047. Thus, $93 \%$ of the explainable variance in this model of data use was at the individual teacher level, and $7 \%$ is at the school level.

Table 3. Teacher Use of Data for School-wide Purposes

\begin{tabular}{|c|c|c|c|c|}
\hline & Model 1 & Model 2 & Model 3 & Model 4 \\
\hline \multicolumn{5}{|l|}{ Level 1} \\
\hline Intercept & $\begin{array}{l}2.735 * * * \\
(.043)\end{array}$ & $\begin{array}{l}2.721 * * * \\
(.036)\end{array}$ & $\begin{array}{l}2.634 * * * \\
(.072)\end{array}$ & $\begin{array}{l}1.062 \\
(.866)\end{array}$ \\
\hline Instructional & & $.234 * * *$ & $.232 * * *$ & $.206 * * *$ \\
\hline Conversations & & $(.027)$ & $(.029)$ & $(.027)$ \\
\hline Teacher Meetings & & $\begin{array}{l}.126 * * * \\
(.027)\end{array}$ & $\begin{array}{l}.118 * * * \\
(.026)\end{array}$ & $\begin{array}{l}.119 * * * \\
(.023)\end{array}$ \\
\hline Teacher Experience & & & $\begin{array}{l}.008 * * \\
(.002)\end{array}$ & $\begin{array}{l}.006 \sim \\
(.002)\end{array}$ \\
\hline Bachelor's & & & $\begin{array}{c}.013 \\
(.057)\end{array}$ & $\begin{array}{c}.007 \\
(.057)\end{array}$ \\
\hline Master's Plus & & & $\begin{array}{c}.062 \\
(.051)\end{array}$ & $\begin{array}{c}.054 \\
(.051)\end{array}$ \\
\hline K-5 Grade Teacher & & & $\begin{array}{l}-.004 \\
(.064)\end{array}$ & $\begin{array}{c}.028 \\
(.062)\end{array}$ \\
\hline 9-12 Grade Teacher & & & $\begin{array}{l}-.200 * \\
(.080)\end{array}$ & $\begin{array}{l}-.053 \\
(.084)\end{array}$ \\
\hline Organizational Climate & & & & $\begin{array}{l}-.027 \\
(.045)\end{array}$ \\
\hline Collective & & & & $.151 * * *$ \\
\hline Responsibility & & & & $(.031)$ \\
\hline Academic Pressure & & & & $\begin{array}{c}.013 \\
(.027)\end{array}$ \\
\hline \multicolumn{5}{|l|}{ Level 2} \\
\hline Organizational Climate & & & & $\begin{array}{c}.064 \\
(.123)\end{array}$ \\
\hline Collective & & & & .265 \\
\hline Responsibility & & & & $(.145)$ \\
\hline Academic Pressure & & & & $\begin{array}{l}-.018 \\
(.171)\end{array}$ \\
\hline Percent Proficient & & & & $\begin{array}{c}.004 \\
(.002)\end{array}$ \\
\hline \multicolumn{5}{|l|}{ Model Statistics } \\
\hline Sigma Squared & .601 & .516 & .512 & .503 \\
\hline Tau & .047 & .029 & .018 & .007 \\
\hline
\end{tabular}


Model 2 shows the relationship between the two measures of collaboration and school-wide data use. When the two teacher level predictors of collaboration were included in the model, the variance at the teacher level was reduced from .601 to .516 . This indicates that the two teacher level predictors measuring the frequency that teachers collaborate explained $14.1 \%$ of the explainable variation at the individual level. Examining these variables separately, both the frequency of instructional conversations and frequency of teacher meetings were positively and significantly related to school-wide data use. More specifically, a standard deviation increase in instructional conversations is associated with about a quarter of a unit (.234) on the four point scale of school-wide data use) increase in data use. Meeting frequency was also positively and significantly related to school-wide data use (.126), but its magnitude was about half that of instructional conversations.

Model 3 adds the set of individual teacher characteristics. The significance and magnitude of the two measures of teacher collaboration stay about the same, even after adding measures of teacher experience, education, and grade level. In this model, teacher experience was significantly related to teacher use of data for school-wide purposes, but the effect was small; every year of experience was related to only .008 additional units on the four-point data use scale. There was no relationship between teacher education level and teacher use of data for school-wide purposes. Finally, there was no difference in teacher use of data for school-wide purposes between elementary and middle school teachers, but being a teacher of grades 9 through 12 was significantly related to lower use of data for school wide purposes. Specifically, high school teachers .2 of a unit lower use of data on the four point scale. The addition of these additional teacher level variables did not explain much additional variance, only $.8 \%$, of the total explainable variance at the teacher level.

Model 4 shows the results of the full model that includes two measures of collaboration, individual teacher characteristics, and three school culture scales measured at both the individual and school levels. Even after adding the school culture variables at level one and level two, there remains a positive and significant relationship between the two measures of teacher collaboration and teacher use of data for school-wide purposes. However, the addition of these variables reduces the magnitude and significance level of the relationship between teacher experience and school-wide data use. Additionally, there is no longer any statistical difference between elementary, middle and high school teacher use of data for school-wide purposes. There is, however, a positive and significant association between teachers' individual perceptions of the collective responsibility of their faculty and teacher use of data for school-wide purposes. There are no significant differences between any of the level 2 culture variables or the percent proficient students in the school and data use.

\section{Summary and Discussion}

The press to use data to inform instruction and school leadership has grown tremendously in the past decade, as more data have been made available through an increase in testing and better technological systems to deliver data to users. Practitioner models of data use and case studies of how data are used in schools suggest that collaboration facilitates data use in 
schools. In this paper we sought further evidence to support the relationship between collaboration and data use.

Our findings indicate that there is an empirical relationship between collaboration and two facets of data use: teachers' use of individual student data and teachers' use of data for school-wide purposes. Our analyses used two measures of collaboration, first, teacher reports of their frequency of conversations with their peers on instructional matters, and second, frequency of teacher meetings with peers. Both measures of collaboration were significantly related to both dimensions of data use. The first measure of collaboration, teachers' instructional conversations with peers, had about twice as strong a relation with each dimension of data use than did frequency of teacher meetings. Importantly, the strength of the relationship between the two measures of collaboration and both individual and school wide data use remained constant even as we controlled for various teacher characteristics and school characteristics.

At the individual level, we also found a few factors related to data use, although they differed between the two dimensions of data use. High school teachers used individual student data less than middle school and elementary school teachers, while there was no difference in individual student data use between the latter. There was also a slight relationship between education levels and teacher use of individual student data; teachers with more than a masters degree were somewhat more likely (i.e. significance at the .10 level) to use individual student data than were teachers with just a Master's degree or teachers with a Bachelor's degree, even after controlling for other individual and school level characteristics. In the full model predicting teachers' use of data for school-wide purposes, only teacher experience was significantly related to this aspect of data use.

In our modeling of data use, we made a decision to include three aspects of school culture organizational climate, collective responsibility, and academic press - at both the teacher and school levels. We did this to acknowledge that individual teachers can have perceptions of these representations of school culture that are distinct from the collective perspective. We found that teachers' individual perceptions of collective responsibility, or the degree to which they reported that all faculty members felt responsible for the broader school environment beyond what is assigned to them, was significantly and positively related to both dimensions of data use. In the model of teacher use of individual student data, we also found a significant relationship between teachers' individual perceptions of academic press, or their sense that the faculty had high expectations for student effort and academic performance, and data use. At the school level, however, we found that none of these three aspects of school culture were significantly related to either data use outcome. This may have been due to both the relatively small sample of schools and the fact that most of the explainable variance in these outcomes was at the teacher, not the school, level.

This research provides important empirical support for the contention that teachers who collaborate use data more frequently. One implication of this is that if we want to increase teachers' use of data, then we should both create opportunities for teachers to meet together to examine data and that we should provide them with the skills to examine data in group 
settings. If data use is commonly a group activity, then productive group interactions become an important aspect of effective decision-making based upon data.

There are also several constraints in our analyses that provide opportunities for additional research. First, collaboration most likely occurs within subgroups in schools, such as grade level or subject matter teams, and further research would explore both the extent and variation of data use and its influence at these levels. Our data did not allow us to decompose schools into these sub-groups, but additional research would model these nested relationships more appropriately. Second, our measures of collaboration are constrained to frequency of teachers' instructional conversations with peers and frequency of teacher meetings; it would be useful to examine other important dimensions of collaboration and their influence on productive data use. For example, leadership, group trust, and team member data analysis skills are all potentially important characteristics of effective team practices that could be modeled in their relationship to data use.

Finally, we must not lose sight of the fact that data use is just a means to school improvement, and this paper provides just a step of evidence towards following this trail. Additional research would link collaboration to data use and data use to important school and student outcomes. The value of using data for school improvement comes from insights gleaned from data that allow teachers and school leaders to sharpen the decisions they make and the resulting strategies they employ to improve student learning opportunities and expand student understanding. This study merely indicates that collaboration facilitates the use of data. That is, teachers tend to examine data more frequently when they meet together. This is not to say that merely providing teachers with collaborative time will increase fruitful data investigations, but that collaboration seems to facilitate teachers' investigation of available data. Much work still needs to be done to understand better how educators interact when they examine data and what influence these discussions about data have on subsequent practice and student learning.

\section{References}

Bernhardt, V. (1998). Data analysis for comprehensive school-wide improvement. Larchmont, NY: Eye on Education.

Boudett, K.P., City, E.A., \& Murnane, R.J. (2005). Data Wise. Cambridge, MA: Harvard Education Press.

Chrispeels, J. H. Castillo, S. Brown, J. (2000). School Leadership Teams: A Process Model of Team Development. School Effectiveness And School Improvement,11(1) 20-56.

Christman, J.B., Neild, R.C., Bulkley, K., Blanc, S., Liu, R, Mitchell, C, \& Travers, E. (2009). Making the Most of Interim Assessment Data. Lessons from Philadelphia. Philadelphia, PA.: Research for Action.

Coburn, C.E. (2001). Collective Sensemaking about Reading: How Teachers Mediate Reading Policy in Their Professional Communities. Educational Evaluation and Policy Analysis, 23(2), 145-170. http://dx.doi.org/10.3102/01623737023002145 
Consortium on Chicago School Research. (2000). Public Use Data Set User's manual. Retrieved from: http://ccsr.uchicago.edu/downloads/69981999_survey_manual.pdf

Daft, R.L. \& Weick, K.E. (1984). Toward a model of organizations as interpretation systems. Academy of Management Review, 9(2), 284-295. MANAGE REV April 1, 1984 vol. 9 no. 2 284-295

Datnow, A., Park, V. \& Wohlstetter, P. (2007). Achieving with data: How high-performing school systems use data to improve instruction for elementary students. Los Angeles, CA: University of Southern California Center on Educational Governance. Retrieved from: http://www.newschools.org/wp/wp-content/uploads/AchievingWithData.pdf

Earl, L., \& Katz, S. (2006). Leading schools in a data-rich world. Thousand Oaks, CA: Corwin Press.

Hamilton, L. S., Stecher, B. M., \& Klein, S. P. (2002). Making sense of test-based accountability in education. Santa Monica, CA: Rand.

Hamilton, L., Halverson, R., Jackson, S., Mandinach, E., Supovitz, J., \& Wayman, J. (2009). Using student achievement data to support instructional decision making. Washington, DC: National Center for Education Evaluation and Regional Assistance, Institute of Education Sciences, U.S. Department of Education. Retrieved from: http://ies.ed.gov/ncee/wwc/pdf/practice_guides/dddm_pg_092909.pdf

Kim, D. (1993). The link between individual and organizational learning. Sloan Management Review. Fall, 37-50. Retrieved from: http://www.iwp.jku.at/Born/mpwfst/03/0312_IVkim.pdf

Lachat, M.A. \& Smith, S. (2005). Practices That Support Data Use in Urban High Schools. Journal of Education for Students Placed At Risk, 10(3), 333-349. http://dx.doi.org/10.1207/s15327671espr1003_7

Lindblom, C.E. \& Cohen, D.K. (1979). Usable knowledge: Social science and social problem solving. New Haven, CT: Yale University Press.

Love, N. (2000). Using data, getting results: Collaborative inquiry for school-based mathematics and science reform. Cambridge, MA: Regional Alliance at TERC.

March, J.G. \& Olsen, J.P. (1975). The uncertainty of the past: Organizational learning under ambiguity. European Journal of Political Research, 3, 147-171. http://dx.doi.org/10.1111/j.1475-6765.1975.tb00521.xz

McDonnell, L. (2005). Assessment and accountability from the policymaker's perspective. In J. Herman and E. Haertel (Eds.), Uses and misuses of data for educational accountability and improvement(pp. 35-54). Chicago, IL: National Society for the Study of Education. http://dx.doi.org/10.1111/j.1744-7984.2005.00024.x

Raudenbush, S.W. \& Bryk, A.S. (2002). Hierarchical linear models: Applications and data analysis methods ( $2^{\text {nd }}$ edition). Thousand Oaks, CA: Sage Publications. 
Simon, H.A. (1955). A Behavioral Model of Rational Choice. The Quarterly Journal of Economics, 69(1), 99-118. http://dx.doi.org/10.2307/1884852

Snipes, J., Doolittle, F. \& Herlihy, C. (2002). Foundations for success: Case studies of how urban school systems improve student achievement. Washington, DC: Council of Great City Schools.

Retrieved

from:

http://www.mdrc.org/sites/default/files/foundations_for_success_fr.pdf

Spillane, J. P. (1999). External Reform Initiatives and Teachers' Efforts to Reconstruct their Practice: The Mediating Role of Teachers' Zones of Enactment. Journal of Curriculum Studies, 31(2). http://dx.doi.org/10.1080/002202799183205

Steele, J.L. \& Boudett, K.P. (2009). The Collaborative Advantage. Educational Leadership, $66(4)$, 54-59.

Retrieved from

http://www.ascd.org/publications/educational-leadership/dec08/vol66/num04/The-Collaborati ve-Advantage.aspx

Stringfield, S., Wayman, J. C., \& Yakimowski-Srebnick, M. E. (2005). Scaling up data use in classrooms, schools, and districts. In C. Dede, J. P. Honan, \& L. C. Peters (Eds.), Scaling up success: Lessons learned from technology-based educational improvement (pp. 133-152). San Francisco, CA: Jossey-Bass.

Cohen, D.K. \& Ball, D. L. (2000).Instructional Innovation: Reconsidering the Story.). Ann Arbor, MI: Study of Instructional Improvement research domains and constructs. Retrieved from: http://www.sii.soe.umich.edu/about/pubs.html .

Supovitz, J.A. \& Klein, V. (2003). Mapping a course for improved student learning: How innovative schools systematically use student performance data to guide improvement. Philadelphia, PA: Consortium for Policy Research in Education. Retrieved from: http://www.cpre.org/images/stories/cpre_pdfs/AC-08.pdf

Supovitz, J.A. (2006). The case for district-based reform: Leading, building, and sustaining school improvement. Cambridge, MA: Harvard Education Press.

Supovitz, J.A. (2009). Can high stakes testing leverage educational improvement? Prospects from the last decade of testing and accountability reform. Journal of Educational Change, 10(2), 211-227. http://dx.doi.org/10.1007/s10833-009-9105-2

Supovitz, J.A., Merrill, E. \& Conger, M. (2010). Productive Teacher Use of Student Performance and Related Data in Professional Learning Communities. Paper presented at the American Educational Research Association Annual Meeting, Denver, Colorado.

Togneri, W. \& Anderson, S.E. (2003). Beyond islands of excellence: What districts can do to improve instruction and achievement in all schools. Washington, DC: Association for Supervision and Curriculum Development. Retrieved from: http://www.learningfirst.org/publications/districts. 
Wiliam, D., \& Leahy, S. (2006, April). A theoretical foundation for formative assessment. Paper presented at the American Educational Research Association Annual Meeting, San Francisco, CA.

Young, V. M. (2006). Teachers' Use of Data: Loose Coupling, Agenda Setting, and Team Norms. American Journal lof Education, 112(4), 521-548. http://dx.doi.org/10.1086/505058 


\section{Appendix A. Items and Scales}

Organizational Climate $($ Alpha $=.89)$

The degree to which the following are a problem in the school (4 pt scale)
a. student absenteeism
b. Lack of parental support or participation
c. Teacher absenteeism
d. Physical conflict among students
e. Robbery, theft, or vandalism at the school
f. Student use of drugs or alcohol
g. Verbal abuse of teachers
h. Conflicts between students and teachers
i. Parents' low education levels

Academic Pressure $($ Alpha $=.93)$

Agreement with the following statements (6 point scale)
a. Teachers in this school expect students to complete every assignment
b. Teachers in this school encourage students to keep trying even when the work is challenging
c. Teachers in this school set high expectations for academic work
d. Teachers in this school think its important that all students do well in their classes

Teacher Collaboration (Alpha $=.91)$

Frequency of conversations with colleagues around the following topics ( 5 point scale)
a. What helps students learn best
b. Development of new curriculum
c. The goals of the school
d. Managing classroom behavior
e. Your instruction
f. Content or performance standards in your subject area

Frequency of Teacher Meetings

How often teachers have had meetings to discuss and plan curriculum and teaching approaches on a 7 point scale consisting of (1) never; (2) about once or twice a year; (3) about once every other month; (4) about once a month; (5) about 2-3 times a month; (6) about once a week; (7) more than once a week.

Collective Responsibility (Alpha $=.91)$

Proportion of teachers in school who feel responsible to (5 point scale):
a. Help maintain discipline in the entire school, not just their classroom
b. Take responsibility for improving the school
c. Set high standards for themselves
d. Feel responsible to help each other do his/her best
e. Feel responsible that all students learn 
Use of Individual Student Data (Alpha $=.91)$

Extent to which data are used by you for the following purposes: ( 4 point scale)

a. Identifying individual students who need remedial assistance

b. Setting learning goals for individual students

c. Tailoring instruction to individual students' needs

d. Developing recommendations for tutoring or other educational services for students

e. Assigning or reassigning students to classes or groups

Use of data for school-wide Purposes (Alpha $=.87)(4$ point scale $)$

Extent to which data are used in the school for the following purposes

a. Identifying areas where teachers need to strengthen their content knowledge or teaching skills

b. Determining topics for professional development

c. Setting school improvement goals

d. Celebrating the achievement of school goals 